\title{
ASSOCIATIONS BETWEEN SEX HORMONE BINDING GLOBULIN AND METABOLIC SYNDROME PARAMETERS IN PREMENOPAUSAL OBESE WOMEN
}

FULYA AKIN, MEHMET BASTEMIR, ESMA ALKIS', BUNYAMIN KAPTANOGLU²

\section{ABSTRACT}

BACKGROUND AND AIMS: The aim of this study was to determine sex hormone binding globulin (SHBG) concentrations in premenopausal obese women and to evaluate the relationships between sex hormones and features of the metabolic syndrome (MetS). Settings and Design: Retrospective cross-sectional analysis was carried out on 350 obese patients aged 25 to 69 years referred to the Department of Endocrinology, Pamukkale University in 2002-2003. MATERIALS AND METHODS: 125 premenopausal euthyroid patients were eligible for this study. Subjects were divided into two groups according to the body mass index (BMI): Group I, women with BMI $<30 \mathrm{~kg} / \mathrm{m}^{2}$ (n = 17) and Group II,, women with BMI $\geq 30 \mathrm{~kg} / \mathrm{m}^{2}(n=108)$. Median SHBG concentration of Group I was $50.1 \mathrm{nmol} / \mathrm{L}$. Group II was divided into two subgroups according to the median SHBG concentration of Group I: subjects with high SHBG levels (SHBG concentration $\geq$ median level of the control group, i.e $\geq 50.1 \mathrm{nmol} / \mathrm{L}$ ) and subjects with low SHBG levels (<50.1 nmol/L). All statistical analyses were performed using SPSS 9.0 software (SPSS Inc.). RESULTS: No significant difference was found in mean age between the low and high SHBG groups. The low SHBG group was significantly heavier, and with higher waist circumference than the high SHBG group. In the low SHBG group, fasting glucose, postprandial glucose and gamma glutamyl transferase (GGT) and free androgen index (FAI) were significantly higher. Lipid profile, blood pressure, uric acid, insulin and HOMA were found similar between two groups. Linear regression analyses revealed that body mass index and FAl were significant, being independent predictors of SHBG concentrations in premenopausal women. $(r=0.365, r$ square $=0.134)$. CONCLUSIONS: It is concluded that low SHBG concentrations may indicate visceral obesity and glucose intolerance in premenopausal women.

Key words: Insulin resistance, metabolic syndrome, obesity, premenopausal women, sex hormone binding globulin.

Department of Endocrinology and Metabolism,

${ }^{1}$ Public Health, ${ }^{2}$ Biochemistry, Pamukkale Üniversitesi

Endokrinoloji ve Metabolizma Hastalıkları, Kınıkı

Kampusü 20070, Denızlı, Turkey

Correspondence:

Dr. Fulya Akın, Pamukkale Üniversitesi Endokrinoloji ve Metabolizma Hastalıkları, Kınıklı Kampusü 20070, Denızı,

Turkey. E-mail: fulyaendo@yahoo.com.tr

\section{INTRODUCTION}

Sex hormone binding globulin (SHBG) is the major binding protein for gonadal steroids in the circulation. ${ }^{[1]}$ It was originally described as a hepatically secreted protein and thereby 
regulating the availability of free steroids to hormone-responsive tissues. ${ }^{[2]}$

In women, increased androgenicity, as reflected by low circulating SHBG concentrations, has been related to hyperinsulinemia, glucose intolerance, and insulin resistance, as well as to the risk of cardiovascular disease and type 2 diabetes. An androgenic sex steroid profile as reflected by low circulating SHBG is also associated with an increased accumulation of abdominal fat in women. ${ }^{[3]}$

At present there is much evidence that insulin may be an important modulator of SHBG concentrations. In vitro, insulin is a potent inhibitor of SHBG production by HepG2 cells $^{[4]}$ and reduces the stimulatory effect of $17 \beta$ estradiol and thyroxine. ${ }^{[5]}$ In vivo, reduced serum SHBG levels may indicate the presence of insulin resistance states with hyperinsulinemia, such as polycystic ovary syndrome ${ }^{[6]}$ or obesity. [7] Furthermore, a recent prospective study identified low levels of SHBG as a risk factor for future diabetes mellitus. ${ }^{[8]}$ Thus, one may argue that low SHBG levels are associated with $\mathrm{CHD}$ by indicating the presence of the insulin resistance / hyperinsulinemia syndrome.

Previous studies have demonstrated that reduced plasma levels of SHBG are related to alterations in several features of the MetS in men and women. ${ }^{[9-12]}$ Most of the research linking low SHBG and high androgens to cardiovascular risk has been restricted to postmenopausal women. [13-15] The aim of this study was to determine SHBG concentrations in premenopausal women who were otherwise healthy, and to evaluate the relationships between SHBG concentrations and features of the MetS.

\section{MATERIALS AND METHODS}

Retrospective cross-sectional analysis was carried out on 350 obese and overweight patients aged 25 to 69 years referred to the Department of Endocrinology and Metabolic Diseases of Pamukkale University hospital in 2002-2003. Records are stored in folders in the institution and the same person retrieved all the data. We studied the Turkish population living in Denizli province of Aegean geographical region of Turkey. Our samples were from the inner part of the Aegean region of Turkey.

All of the patients were obese and overweight, BMI $>25 \mathrm{~kg} / \mathrm{m}^{2}$. Patients who were under treatment with contraceptive drugs or hormone replacement therapy (HRT), or diagnosed with polycystic ovary disease, thyroid disease, chronic renal failure, chronic hepatopathy or cancer, were excluded from the study. Presence of medical conditions was assessed through self-report. Thyroid status was assessed by freeT3 (fT3), freeT4 (fT4), and thyrotrophin (TSH) levels.

Insulin resistance was estimated by homeostatic model assessment ratio formula [HOMA-IR $=($ Fasting plasma insulin $(\mu \mathrm{lU} / \mathrm{mL}) \times$ fasting plasma glucose $(\mathrm{mmol} / \mathrm{L})) / 22,5] .{ }^{[16]}$ Free androgen index (FAI) was used to estimate the amount of testosterone unbound by SHBG and thus, immediately biologically active. FAI was calculated as the ratio of testosterone (ng/ $\mathrm{ml})$ to SHBG $(\mathrm{ng} / \mathrm{mL}) \times 100{ }^{[3]}$ The definition of menopausal status was in accordance with the following criteria: ${ }^{[17]}$

-Women presenting normal menses or who in any case reported at least 10 cycles in the 
previous year and without climacteric-related symptoms, and having follicle stimulating hormone levels lower than $12.75 \mathrm{IU} / \mathrm{l}$, were included in the premenopausal group. 125 premenopausal euthyroid patients were eligible for this study (mean age: $35.6 \pm 9.35$ Patients were divided into two groups according to the body mass index (BMI): Group I (overweight women), women with $\mathrm{BMl}<30 \mathrm{~kg} / \mathrm{m}^{2}(\mathrm{n}=17)$ and Group II (obese women), women with $\mathrm{BMI}>$ or $=30 \mathrm{~kg} / \mathrm{m}^{2}(\mathrm{n}=108)$. The values of the SHBG concentrations were scattered and median SHBG concentrations were used. Median SHBG concentration of Group I was $50.1 \mathrm{nmol} / \mathrm{L}$. Group II (obese women) was divided into two subgroups according to the median SHBG concentration of Group I. Women with high SHBG levels (SHBG concentration $>$ or $=$ median level of the control group, i.e. $>$ or $=50.1 \mathrm{nmol} / \mathrm{L})(n=26)$ and women with low SHBG levels $(<50.1 \mathrm{nmol} / \mathrm{L})$ $(n=82)$.

\section{Anthropometric measurements}

Height and weight were measured in light clothing without shoes. Body height was measured by a statometer and body weight by digital electronic weighing scales. Body mass index (BMI) was calculated as weight in kilograms divided by the square of height in meters. Waist circumferences were measured using a flexible measuring tape, midway between the xiphoid and the umbilicus during the midinspiratory phase, respectively. Anthropometric measurements were carried out three times by a single tester. Body water and fat distribution was assessed by multiple frequency bioelectric impedance measurement with a portable impedance analyzer (Tanita, Tokyo, JAPAN).

\section{Blood pressure}

The average of two measurements of blood pressure (BP) with the subject in the sitting position was taken at a 2 to 3 min interval after resting for at least $15 \mathrm{~min}$.

\section{Metabolic syndrome definition}

The metabolic syndrome (MetS) was defined by an NIH Expert Panel (referred to as the ATPIII guidelines). ${ }^{[18]}$ MetS was defined as presence of three or more of the following:

- Waist circumference $(\mathrm{cm})>88$

- Systolic BP > 130mm Hg or diastolic BP > $85 \mathrm{mmHg}$

- HDL cholesterol $<50 \mathrm{mg} / \mathrm{dL}$

- Impaired fasting glucose (IFG), fasting plasma glucose $>110 \mathrm{mg} / \mathrm{dL}$

- Triglycerides $>150 \mathrm{mg} / \mathrm{dL}$

\section{Laboratory analyses}

Serum levels of fasting and postprandial glucose, total cholesterol, triglyceride, HDLcholesterol, LDL-cholesterol and uric acid were analyzed with commercial kits (Beckman - Coulter, USA) in an autoanalyzer (Beckman - Coulter LX-20, USA) while the levels of serum insulin, fT3, fT4, TSH, testosterone, estradiol (E2), sex-hormone binding protein, $\mathrm{FSH}$ and $\mathrm{LH}$ were determined in an immunanalyzer (Immulite 2000, USA) using chemiluminescence method.

\section{Statistical analyses}

Descriptive statistics, proportions for categorical variables and means, median and standard deviations for continuous variables were used to describe the study groups. Comparisons between Group I and Group II were performed by Mann Whitney-U test. Comparisons between low SHBG and high SHBG groups were 
performed by Student's t test. The multivariant regression analysis was performed using backward method. Regression test was used to analyze the relationship between SHBG, body weight, BMI, waist circumference, fat percentage, fasting glucose, postprandial glucose, gamma glutamyl transferase (GGT) and free androgen index (FAI). All statistical analyses were performed using SPSS 9.0 software (SPSS Inc.).

$P$ value less than 0.05 was considered as significant.

Table 1: Patient characteristics (means and S.E.M.)

\begin{tabular}{lc}
\hline & $\begin{array}{c}\text { Premenopausal } \\
\text { women }(N=125)\end{array}$ \\
\hline Age (years) & $35.6 \pm 9.35$ \\
Weight $(\mathrm{kg})$ & $88.96 \pm 16.11$ \\
Height $(\mathrm{cm})$ & $158.44 \pm 5.05$ \\
BMl $\left(\mathrm{kg} / \mathrm{m}^{2}\right)$ & $35.39 \pm 6.07$ \\
Waist $(\mathrm{cm})$ & \\
circumferences & $95.45 \pm 11.94$ \\
Fat (Tanita) & $41.95 \pm 7.98$ \\
\hline
\end{tabular}

\section{RESULTS}

The patient characteristics (means and S.E.M.) of the studied group and the measured parameters are shown in table 1.

Median SHBG concentration of Group I was $50.1 \mathrm{nmol} / \mathrm{L}$ (mean value was $64.28 \mathrm{nmol} / \mathrm{L}$ with a standard deviation of $50.27 \mathrm{nmol} / \mathrm{L}$ ). The values of the SHBG concentrations were scattered, and median SHBG concentrations were used.

Characteristics and study parameters in women in Group I and Group II are shown in table 2. Subjects in Group I had lower BMI, with significantly lower waist circumference, fat $\%$, systolic and diastolic blood pressure, uric acid, and GGT level $(P=0.000, P=0.000$, $P=0.000, P=0.000, P=0.004, P=0.003$, $P=0.029)$.

Table 2: Characteristics of the Group I and Group II

\begin{tabular}{|c|c|c|c|c|c|}
\hline & \multirow{2}{*}{$\begin{array}{c}\text { Group I }(n=17) \\
B M I<30\end{array}$} & \multirow{2}{*}{$\begin{array}{l}\text { Group II }(n=108) \\
B M I>30 \text { or }=30\end{array}$} & \multicolumn{2}{|c|}{$95 \% \mathrm{Cl}$} & \multirow[t]{2}{*}{$P$ value } \\
\hline & & & Lower & Upper & \\
\hline Median SHBG (nmol/L) & 50.1 & 34.8 & & & \\
\hline Age (years) & $33.12 \pm 10.65$ & $36.02 \pm 9.03$ & -7.68 & 1.88 & 0.509 \\
\hline Weight (kg) & $69.58 \pm 8.02$ & $92.02 \pm 14.90$ & -27.34 & -17.54 & 0.000 \\
\hline BMI $\left(\mathrm{kg} / \mathrm{m}^{2}\right)$ & $27.66 \pm 2.08$ & $36.62 \pm 5.55$ & -10.43 & -7.50 & 0.000 \\
\hline Fat \% (Tanita) & $33.45 \pm 4.83$ & $43.28 \pm 7.57$ & -13.70 & -5.95 & 0.000 \\
\hline Waist $(\mathrm{cm})$ & $81.00 \pm 6.02$ & $97.75 \pm 11.01$ & -20.41 & -13.08 & 0.000 \\
\hline Systolic blood pressure (mmHg) & $109.12 \pm 12.78$ & $123.17 \pm 16.15$ & -22.21 & -5.90 & 0.000 \\
\hline Diastolic blood pressure (mmHg) & $72.94 \pm 9.20$ & $80.82 \pm 9.61$ & -12.82 & -2.93 & 0.004 \\
\hline Fasting glucose $(\mathrm{mg} / \mathrm{dL})$ & $95.29 \pm 8.73$ & $105.85 \pm 27.56$ & -23.93 & 2.82 & 0.059 \\
\hline 2h Postprandial glucose (mg/dL) & $109.40 \pm 24.47$ & $115.70 \pm 46.60$ & -30.71 & 18.11 & 0.620 \\
\hline Fasting insulin $(\mu \mathrm{lU} / \mathrm{mL})$ & $10.37 \pm 2.30$ & $13.62 \pm 6.11$ & -5.03 & -1.47 & 0.052 \\
\hline HOMA -IR & $2.48 \pm 0.65$ & $3.56 \pm 1.91$ & -1.61 & -0.55 & 0.025 \\
\hline Total cholesterol (mg/dL) & $184.13 \pm 38.36$ & $187.42 \pm 34.31$ & -22.33 & 15.75 & 0.594 \\
\hline Triglycerides (mg/dL) & $120.47 \pm 58.01$ & $142.02 \pm 119.90$ & -84.07 & 40.97 & 0.961 \\
\hline LDL cholesterol (mg/dL) & $112.00 \pm 35.79$ & $113.00 \pm 27.68$ & -16.44 & 14.44 & 0.480 \\
\hline HDL cholesterol (mg/dL) & $49.75 \pm 11.01$ & $44.97 \pm 11.56$ & -1.34 & 10.89 & 0.232 \\
\hline Uric acid (mg/dL) & $3.69 \pm 0.85$ & $4.77 \pm 1.23$ & -1.87 & -0.29 & 0.003 \\
\hline Testosterone (ng/dL) & $113.80 \pm 173.13$ & $65.96 \pm 56.24$ & -62.62 & 158.31 & 0.225 \\
\hline Estradiol (pg/mL) & $101.59 \pm 64.89$ & $114.70 \pm 99.51$ & -51.01 & 24.80 & 0.716 \\
\hline Free androgen index (FAl) & $3.90 \pm 7.32$ & $2.20 \pm 2.32$ & -3.24 & 6.64 & 0.768 \\
\hline Mean SHBG (nmol/L) & $64.28 \pm 50.27$ & $42.19 \pm 30.72$ & -6.29 & 50.47 & 0.032 \\
\hline $\mathrm{GGT}(\mathrm{mg} / \mathrm{dL})$ & $13.36 \pm 4.15$ & $20.26 \pm 11.61$ & -13.92 & 0.13 & 0.029 \\
\hline
\end{tabular}

$95 \% \mathrm{Cl}: 95$ percent confidence interval, $P$ value: less than 0.05 was considered as significant, BMI: Body mass index. 
Table 3: Study parameters in obese women (group II) with low and high SHBG group

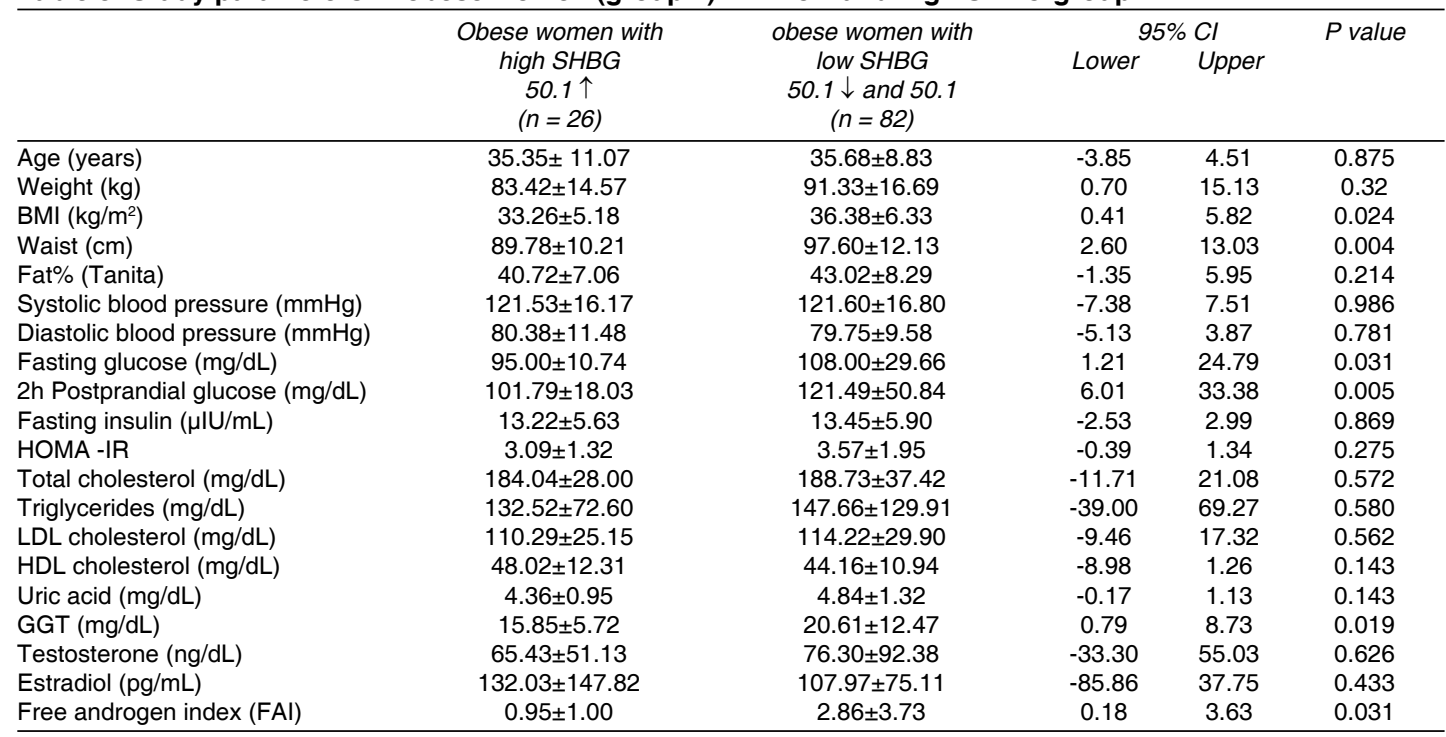

$95 \% \mathrm{Cl}: 95$ percent confidence interval, $P$ value: less than 0.05 was considered as significant.

HOMA values were significantly lower and SHBG concentrations were significantly higher in this group as well $(P=0.025, P=0.025)$.

Group II (our obese group) was divided into two subgroups according to the median SHBG concentration of the Group I. The obese women with SHBG concentrations $>50.1 \mathrm{nmol} / \mathrm{L}$ were regarded as the group with high SHBG and women with SHBG concentrations $<50.1 \mathrm{nmol} / \mathrm{L}$ were regarded as the group with low SHBG.

The study parameters of the obese subgroups are shown in table 3.

No significant difference was found in mean age between low and high SHBG group $(P=0.875)$.

The low SHBG group was significantly heavier, and had higher BMI, with higher waist circumference than high SHBG group $(P=0.032, P=0.024, P=0.004)$.

In the low SHBG group, fasting glucose, postprandial glucose, GGT and FAl levels was significantly higher $(P=0.001, P=0.005$, $P=0.019, P=0.031$ ).

Similar lipid profile (TG, HDL cholesterol), blood pressure, uric acid, insulin and HOMA were found between two groups $(P=0.580$, $P=0.138, P=0.986, P=0.781, P=0.143$, $P=0.869, P=0.275)$.

Significant correlations of the SHBG with other study parameters using multiple linear regression analysis, with SHBG as the dependent variable are shown in table 4.

Linear regression analyses (backward) revealed that free androgen index (FAl) was a significant 
Table 4: Significant linear correlation of the SHBG with other study parameters in multiple regression analysis model with SHBG as dependent variable (whole group $n=125$ )

\begin{tabular}{lccccc}
\hline & $\beta$ & $p$ & OR & \multicolumn{2}{c}{$95 \% \mathrm{Cl}$} \\
\cline { 5 - 6 } & & & & Lower & Upper \\
\hline $\begin{array}{l}\text { Free androgen } \\
\text { index }\end{array}$ & -1.63 & 0.012 & 0.196 & 0.055 & 0.699 \\
\hline
\end{tabular}

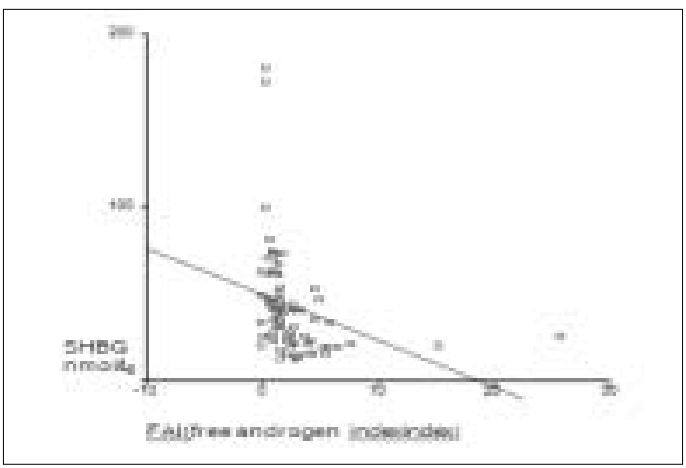

Figure 1: Correlation between sex hormone binding globulin (SHBG) and free androgen index (FAI)

independent predictor of SHBG concentrations in premenopausal women $(P=0.012)$ [Figure 1].

\section{DISCUSSION}

Whether SHBG is a causal agent of the MetS or merely represents a marker for primary endocrine abnormalities leading to these metabolic alterations remains unclear at the present time. We investigated the interactions of a variety of clinical and laboratory parameters characterizing the metabolic syndrome. We focused on premenopausal women, because most of the previous studies were on postmenopausal subjects.

Tchernof, Garaulet and coworkers performed similar studies in premenopausal women too. ${ }^{[3,19]}$ But the size of our study group was larger than Tchernof and Garaulet's groups. The biggest epidemiological study about SHBG and cardiovascular risk in multiethnic premenopausal and perimenopausal women is the SWAN (Study of Women Across the Nation) study. They reported that low SHBG and high $\mathrm{FAl}$ were strongly associated with $C V$ risk factors even after controlling for BMI. ${ }^{[20]}$ In our study FAl was used to estimate the amount of testosterone unbound by SHBG, thus biologically active like SWAN group. In the present study, obese women with low SHBG concentrations had significantly higher FAI. The cause and effect relationships between SHBG concentrations and MetS components in obese women could not be assessed because of the cross sectional nature of our study.

Another big comprehensive study was performed by Hajamour et al. ${ }^{[12]}$ Their data were obtained from Quebec Family Study (QFC). They reported that plasma SHBG level may represent a significant predictor of the MetS in men and premenopausal women. The association between plasma SHBG and variables of glucose homeostasis were significant in premenopausal women. ${ }^{[7]}$ Our results also confirm their data. Our study shows strong relationships between SHBG and anthropometric measurements and fasting glucose, postprandial glucose, GGT levels and FAI in premenopausal women. Linear regression analyses (backward) revealed that $\mathrm{BMI}$ and $\mathrm{FAl}$ were significant independent predictors of SHBG concentrations in premenopausal women [Figure 1].

The accelerated accretion of adipose tissue in the intra-abdominal region coincident with the onset of menopause may explain part of 
the increased risk of cardiovascular disease in postmenopausal women. ${ }^{[4]}$ But premenopausal women showed gynoid type obesity, with a smaller abdominal perimeter. They were lowest in most abdominal fat distribution parameters. ${ }^{[19]}$ In this study, we found that total or intra-abdominal obesity mediated an important part of the relation between low SHBG and an altered metabolic profile by using $\mathrm{BMI}$ and waist circumference. The results of the present study are concordant with previous investigators. ${ }^{[3,21-23]}$ Our obese group showed upper body obesity, and had higher waist circumference and higher HOMA value than overweight subjects. Higher uric acid level and blood pressure was found as expected. Hyperuricemia is reported to be an inherent component of MetS and could be used as a simple marker for insulin resistance.

Low SHBG frequently coincides with components of MetS, such as low levels of HDL cholesterol and high levels of triglycerides and apolipoprotein B. ${ }^{[1,24,25]}$ In this study, no significant difference was found in mean insulin concentrations, HOMA index, blood pressure, triglycerides, HDL and uric acid between the low and high SHBG groups. Determinants of SHBG blood concentrations are likely to change on passing from premenopausal to postmenopausal status. ${ }^{[26]} \mathrm{FAl}$ is an important determinant of SHBG in both premenopausal and postmenopausal women as expected. Our finding also confirms these results. It is known that estrogens protect pancreatic $\beta$-cells from apoptosis and have insulinotrophic effects. ${ }^{[27]}$ In postmenopausal status this effect is lost and insulin levels decrease. The positive effect of estradiol on SHBG levels is probably stronger in premenopausal women than in postmenopausal women. That is why SHBG didn't correlate insulin resistance and MetS component in premenopausal obese women.

In a recent study, it has been noted that after menopause, the impact of insulin resistance on SHBG level seems more important than estradiol. Therefore, it could be argued that SHBG level can be correlated with insulin resistance for postmenopausal women. ${ }^{[28]}$

The major difficulty with our study is that values of the SHBG concentrations were scattered. The mean value was $64.2 \mathrm{nmol} / \mathrm{L}$ with SD of 50.3 , therefore we used median SHBG concentration to show the significance of the work. A similar study was designed by Cikim et al. ${ }^{[29]}$ They studied 307 premenopausal women. They used median SHBG levels too. Their low SHBG group was significantly younger, with higher waist-to-hip ratio (WHR). Triglycerides, uric acid, insulin and HOMA values were significantly lower their low SHBG group. Their multivariant regression analyses showed age and uric acid concentrations in the whole group. They reported that low SHBG concentrations may indicate a severe degree of insulin resistance in premenopausal women. But in our study, no significant difference was found in mean age between low and high SHBG group. The low SHBG group was significantly heavier and had higher BMI with higher waist circumference than high SHBG group. Although fasting glucose, postprandial glucose, GGT levels and FAI were significantly higher in our low SHBG group, lipid profile (TG, HDL cholesterol), blood pressure, uric acid, insulin and HOMA were found similar between the two groups. 
In summary, according to our findings, SHBG levels didn't correlate with insulin resistance in premenopausal obese women. Linear regression analyses (backward) demonstrated that BMI and FAl were significant independent predictors of SHBG concentrations in premenopausal obese women. It is concluded that low SHBG concentrations may indicate visceral obesity and glucose intolerance in premenopausal obese women.

\section{REFERENCES}

1. Panzer $C$, Wise $S$, Fantini $G$, Kang D, Munarriz $\mathrm{R}$, Guay A. Impact of oral contraceptives on sex hormone-binding globulin and androgen levels: A retrospective study in women with sexual dysfunction. J Sex Med 2006;3:104-13.

2. Kahn SM, Hryb DJ, Nakhla AM, Romas NA, Rosner NA. Sex hormone-binding globulin is synthesized in target cells. J Endocrinol 2002;175:113-20.

3. Tchernof A, Toth MJ, Poehlman ET. Sex hormone-binding globulin levels in middle-aged premenopausal women: Association with visceral obesity and metabolic profile. Diabetes Care 1999;22:1875-81.

4. Loukovaara $M$, Carson $M$, Adlercreutz $H$. Regulation of production and secretion of sex hormone-binding globulin in HepG2 cell cultures by hormones and growth factors. $\mathrm{J}$ Clin Endocrinol Metab 1995;80:160-4.

5. Plymate SR, Matej LA, Jones RE, Friedl K. Inhibition of sex hormone-binding globulin production in the human hepatoma (HepG2) cell line by insulin and prolactin. J Clin Endocrinol Metab 1988;67:460-4.

6. Meirow D, Yossepowitch O, Rosler A, Brzezinski A, Schenker JG, Laufer $\mathrm{N}$, et al. Insulin resistant and non-resistant polycystic ovary syndrome represent two clinical and endocrinological subgroups. Hum Reprod 1995;10:1951-6.

7. Pasquali R, Casimirri F, Cantobelli S, Melchionda
N, Morselli-Labate AM, Fabbri R, et al. Effect of obesity and body fat distribution on sex hormones and insulin in men. Metabolism 1991;40:101-4.

8. Lindstedt $\mathrm{G}$, Lundberg $P A$, Lapidus $L$, Lundgren $\mathrm{H}$, Bengtsson C, Bjorntorp P. Low sex hormonebinding globulin concentration as independent risk factor for development of NIDDM: 12-yr followup of population study of women in Gothenburg, Sweden. Diabetes 1991;40:123-8.

9. Tchernof A, Despres JP. Sex steroid hormones, sex hormone-binding globulin and obesity in men and women. Horm Metab Res 2000;32:526-36.

10. Haffner SM, Katz MS, Dunn JF. Increased upper body and overall adiposity is associated with decreased sex hormone binding globulin in postmenopausal women. Int $\mathrm{J}$ Obestet 1991;15:471-8.

11. Pugeat $M$, Moulin $P$, Cousin $P$, Fimbel $S$, Nicolas $\mathrm{MH}$, Crave JC, et al. Interrelations between sex hormone-binding globulin (SHBG), plasma lipoproteins and cardiovascular risk. J Steroid Biochem Molec Biol 1995;53:567-72.

12. Hajamor S, Despres JP, Couillard C, Lemieux $S$, Tremblay A, Prud'homme D. Relationship between sex hormone-binding globulin levels and features of the metabolic syndrome. Metabolism 2003;52:724-30.

13. Reinecke H, Bogdanski J, Woltering A, Breithard G, Assmann G, Kerber S, et al. Relation of serum levels of sex hormone binding globulin to coronary heart disease in postmenopausal women. Am J Cardiol 2002;90:364-8.

14. Phillips GB, Pinkernell BH, Jing TY. Relationship between serum sex hormones and coronary artery disease in postmenopausal women. Arterioscler Thromb Vasc Biol 1997;17:695-701.

15. Skalba $P$, Wojtowicz M, Sikora J. Androgen and SHBG serum concentrations in late post-menopause women. Med Sci Monit 2003;9:CR152-6.

16. Matthews DR, Hosker JP, Rudenski AS, Naylor BA, Treacher DF, Turner RC. Homeostasis model assessment: Insulin resistance and 
beta-cell function from fasting plasma glucose and insulin concentrations in man. Diabetologia 1985;28:412-9.

17. Lukanova A, Lundin E, Jacquette AZ, Muti P, Mure A, Rinaldi S, et al. Body mass index, circulating levels of steroid hormones, IGF-1 and IGF-binding protein-3: A cross-sectional study in healthy women. Eur J Endocrinol 2004;150:161-71.

18. Expert Panel on Detection, Evaluation, and Treatment of High Blood Cholesterol in Adults. Executive Summary of The Third Report of The National Cholesterol Education Program (NCEP) Expert Panel on Detection, Evaluation, And Treatment of High Blood Cholesterol In Adults (Adult Treatment Panel III). JAMA 2001;285: 2486-97.

19. Garaulet M, Perez-Llamas F, Fuente T, Zamora S, Tebar FJ. Anthropometric, computed tomography and fat cell data in an obese population: Relationship with insulin, leptin, tumor necrosis factor-alpha, sex hormone-binding globulin and sex hormones. Eur J Endocrinol 2000;143: 657-66.

20. Sutton-Tyrrell K, Wildman RP, Matthews KA, Chae C, Lasley BL, Brockwell S, et al. Sex hormonebinding globulin and the free androgen index are related to cardiovascular risk factors in multiethnic premenopausal and perimenopausal women enrolled in the study of women across the nation (SWAN). Circulation 2005;111:1242-9.

21. Ivandic A, Prpic-Krizevac I, Sucic M, Juric M. Hyperinsulinemia and sex hormones in healthy premenopausal women: Relative contribution of obesity, obesity type and duration of obesity. Metabolism 1998;47:13-9.

22. Puder JJ, Varga S, Kraenzlin, De Geyter C, Keller U, Müler B. Central fat excess in polycystic ovary syndrome: Relation to low-grade inflammation and insulin resistance. J Clin Endocrinol Metab 2005;90:6014-21.
23. Tanko LB, Bruun JM, Alexandersen $P$, Bagger YZ, Richelsen B, Christiansen C, et al. Novel associations between bioavailable estradiol and adipokines in elderly women with different phenotypes of obesity: Implications for atherogenesis. Circulation 2004;110:2246-52.

24. Tchernof A, Labrie F, Belanger A, Prud'homme D, Bouchard C, Tremblay A, et al. Relationships between endogenous steroid hormone, sex hormone-binding globulin and lipoprotein levels in men: Contribution of visceral obesity, insulin levels and other metabolic variables. Atherosclerosis 1997;133:235-44.

25. Hergenc G, Schulte H, Assmann G, von Eckardstein A. Associations of obesity markers, insulin and sex hormones with HDL cholesterol levels in Turkish and German individuals. Atherosclerosis 1999;145:147-56.

26. Pasquali R, Vicennati V, Bertazzo D, Casimirri F, Pascal G, Tortelli O, et al. Determinants of sex hormone-binding globulin blood concentrations in premenopausal and postmenopausal women with different estrogen status. Metabolism 1997;46:5-9.

27. Le May C, Chu K, Hu M, Ortega CS, Simpson ER, Korach KS, et al. Estrogens protect pancreatic beta-cells from apoptosis and prevent insulindeficient diabetes mellitus in mice. Proc Natl Acad Sci USA 2006;103:9232-7.

28. Akin F, Bastemir M, Alkis E. Effect of Insulin sensitivity on SHBG levels in premenopausal versus postmenopausal obese women. Adv Ther 2007;24:1192-202.

29. Cikim AS, Ozbey N, Sencer E, Molvalilar S, Orhan $\mathrm{Y}$. Associations among sex hormone binding globulin concentrations and characteristics of the metabolic syndrome in obese women. Diabetes Nutr Metab 2004;17:290-5.

Source of Support: Nil, Conflict of Interest: None declared. 